IZA DP No. 9712

Does Medicaid Coverage for Pregnant Women Affect Prenatal Health Behaviors?

Dhaval M. Dave

Robert Kaestner

George L. Wehby

February 2016 


\title{
Does Medicaid Coverage for Pregnant Women Affect Prenatal Health Behaviors?
}

\author{
Dhaval M. Dave \\ Bentley University, NBER and IZA \\ Robert Kaestner \\ University of Illinois at Chicago and NBER \\ George L. Wehby \\ University of lowa and NBER
}

Discussion Paper No. 9712

February 2016

\author{
IZA \\ P.O. Box 7240 \\ 53072 Bonn \\ Germany \\ Phone: +49-228-3894-0 \\ Fax: +49-228-3894-180 \\ E-mail: iza@iza.org
}

\begin{abstract}
Any opinions expressed here are those of the author(s) and not those of IZA. Research published in this series may include views on policy, but the institute itself takes no institutional policy positions. The IZA research network is committed to the IZA Guiding Principles of Research Integrity.

The Institute for the Study of Labor (IZA) in Bonn is a local and virtual international research center and a place of communication between science, politics and business. IZA is an independent nonprofit organization supported by Deutsche Post Foundation. The center is associated with the University of Bonn and offers a stimulating research environment through its international network, workshops and conferences, data service, project support, research visits and doctoral program. IZA engages in (i) original and internationally competitive research in all fields of labor economics, (ii) development of policy concepts, and (iii) dissemination of research results and concepts to the interested public.
\end{abstract}

IZA Discussion Papers often represent preliminary work and are circulated to encourage discussion. Citation of such a paper should account for its provisional character. A revised version may be available directly from the author. 
IZA Discussion Paper No. 9712

February 2016

\section{ABSTRACT \\ Does Medicaid Coverage for Pregnant Women Affect Prenatal Health Behaviors?*}

Despite plausible mechanisms, little research has evaluated potential changes in health behaviors as a result of the Medicaid expansions of the 1980s and 1990s. In this paper, we provide the first national study of the effects of Medicaid on health behaviors for pregnant women, which is a group of particular interest given evidence of the importance of prenatal health to later life outcomes. We exploit exogenous variation from the Medicaid income eligibility expansions for pregnant women during late-1980s through mid-1990s to examine the effects of these policy changes on smoking, weight gain and other maternal health indicators. We find that the 13 percentage point increase in Medicaid eligibility during the study period was associated with approximately a 3 percent increase in smoking and a small increase in pregnancy weight gain for most of the sample. The increase in smoking, which is a significant cause of poor infant health, may partly explain why Medicaid expansions have not been associated with substantial improvement in infant health.

JEL Classification: D1, H0, I12, I13, I18

Keywords: Medicaid, insurance, moral hazard, health, smoking, weight, prenatal care, infant health

Corresponding author:

Dhaval Dave

Department of Economics

Bentley University

175 Forest Street

Waltham, MA 02452

USA

E-mail: ddave@bentley.edu

\footnotetext{
* The authors are grateful to Grace Bagwell, Seth Freedman, Tina Marsh, Joshua Pinkston, Jennifer Trudeau, Wen You and Joshua Graff Zivin for very helpful comments.
} 


\section{Introduction}

Between 1990 and 2010, the share of births in the U.S. covered by Medicaid increased from 28\% to $44 \%$ (Curtin et al, 2013). Much of this increase is due to the expansion of Medicaid income eligibility thresholds for pregnant women that started in the late 1980s and continued through the mid-1990s. The purpose of expanding Medicaid coverage was to reduce the rate of uninsured pregnant women, increase the use of timely medical care (e.g., prenatal care), improve infant health, and narrow socioeconomic health disparities (National Commission to Prevent Infant Mortality 1988).

While the logic of the argument underlying the expansion of Medicaid coverage for pregnant women is intuitive, the evidence to support its validity is not as strong. Generally, there is evidence that expanded Medicaid coverage increased the use of prenatal care, but evidence that Medicaid has improved infant health is less robust (Currie and Gruber 1996; Howell 2001; Centers for Disease Control and Prevention 2002; Hadley 2003; Levy and Meltzer 2004). For example, descriptive evidence presented in Figure 1 suggests that infant health, as measured by rates of low birth weight and preterm birth, have generally worsened or minimally changed during the last 20 years for groups most likely to have benefited from Medicaid expansions: non-Hispanic Black and Hispanic mothers and low-educated mothers.

One possible explanation for this somewhat counterintuitive finding is that health insurance creates incentives to change health behaviors along with lowering the price of medical care. Insurance lowers the price of treating an illness, for example, an adverse medical outcome for either the mother or child, which may, on the margin, cause a reduction in maternal efforts to prevent the occurrence of such events (ex-ante moral hazard). In addition, Medicaid coverage entails an income effect from the saved out-of-pocket expenditures and from spending on health insurance premiums (in the case of substitution of private for public insurance). This additional income may be used to purchase goods that improve infant health, but also goods that may harm infant health (e.g., cigarettes).

Relatively little research has examined potential consequences of expanded Medicaid coverage on health behaviors of pregnant women. In this study, we use the plausibly exogenous variation in health 
insurance coverage resulting from the Medicaid expansions to examine the impact of changes in health insurance on the prenatal behaviors and health indicators of pregnant women. We assess whether the expansion of Medicaid eligibility and its associated increase in Medicaid coverage changed pregnant women's health behaviors such as smoking and nutrition, as approximated by weight gain during pregnancy. We also examine other pregnancy-related health indicators that may reflect health behavior such as gestational diabetes, pregnancy-associated hypertension, and anemia that are related to weight gain, diet and exercise.

Understanding whether the expansion of Medicaid affected health behaviors of pregnant women is particularly important given the documented links between prenatal (in utero) health and adult outcomes (Almond and Currie, 2011; Currie, 2009). The focus on Medicaid is especially salient because of the relative disadvantage in terms of socioeconomic status and health of the Medicaid population. For instance, in the sample of women we study, the baseline prevalence of prenatal smoking among loweducated, unmarried mothers was $40 \%$ compared to $5 \%$ among higher-educated married mothers.

Our research also adds to the sparse literature on ex ante moral hazard and extends the analysis of the effects of Medicaid coverage to health behaviors. While ex ante moral hazard is nearly always mentioned as a theoretical consequence of health insurance, for example, in reviews by Cutler and Zeckhauser (2000) and Kenkel (2000), relatively few empirical studies have assessed its importance and these few studies have not produced a consensus finding. Similarly, while there have been many studies of the effects of the Medicaid expansions on insurance coverage, health care use and health, there are only two studies that we are aware of that assess whether the expansions adversely affected health behaviors: the Oregon Medicaid Experiment (Baicker et al. 2013) and Bhattacharya et al (2011). Neither of these studies included pregnant women and neither addressed the potential problems in identifying the ex ante moral hazard effect from an income effect, or accounted for the indirect effect of health insurance on behaviors that works through greater contact with health care providers who provide health information and counseling. We provide the first national study of the effects of Medicaid on health behaviors, and the first such study for pregnant women. 
Estimates from this study indicate that expansions in Medicaid eligibility were significantly associated with increases in smoking and increases in weight gain during pregnancy. We also find some suggestive evidence of an increase in conditions such as gestational diabetes, which may partly reflect behavioral pathways. While the income effect of gaining publicly-financed insurance is potentially large and can explain a substantial portion of the increase in smoking, it is not enough to explain the entire effect and thus it is likely that there were insurance induced changes in behavior due to ex ante moral hazard. Finally, we find no evidence that increased contact with health care providers affected health behaviors of pregnant women.

\section{Relevant Literature}

While the theory underlying ex ante moral hazard is well developed, the empirical literature is relatively sparse, particularly with respect to health insurance, as there is a somewhat more developed literature for other types of insurance. ${ }^{1}$

Courbage and Coulon (2004) examined the effect of having private health insurance coverage on smoking and exercise among British Households using both classical and instrumental variables regression approaches. The authors reported that there were no differences in health behaviors between the privately insured and those without such insurance. Kelly and Markowitz (2009) and Bhattacharya et al. (2011) assessed whether health insurance coverage (public and private) among working adults was associated with body weight. The two studies reached different conclusions. Kelly and Markowitz (2009) reported a small, positive, but not statistically significant effect of insurance on body mass index (BMI) and the probability of being overweight whereas Bhattacharya et al. (2011) reported relatively large effects of insurance on bodyweight and obesity. Both of these studies used an instrumental variables (IV) approach to address the non-random selection into insurance coverage. ${ }^{2}$ Stanciole (2008) also studied the

\footnotetext{
${ }^{1}$ See, for instance, studies relating prevention and accidents to automobile insurance (Chiappori 2000; Cohen and Dehejia 2004) and studies relating workplace injuries to workers' compensation benefits (Ruser 1985, 1991; Kaestner and Carroll 1997; Fortin and Lanoie 2000).

${ }^{2}$ Kelly and Markowitz (2011) utilize firm size as instruments. Bhattacharya et al. (2011) use firm size, supplemented with state expansions in the Medicaid eligibility between 1989 and 2004, as instruments.
} 
association between health insurance and behaviors using a bivariate probit approach and reported that insurance was significantly associated with greater smoking, less exercise, and more obesity.

Two other papers used quasi-experimental approaches. Card et al. (2008) used a regression discontinuity research design to study the effects of obtaining Medicare at age 65 on various health behaviors and preventive healthcare utilization. They found no significant effects of Medicare on smoking, exercise, or obesity, nor did they find strong effects on preventive services such as obtaining a mammogram. Klick and Stratmann (2007) evaluated whether state mandated, private health insurance coverage for the treatment of diabetes was associated with body mass index among diabetics. Results from this state-level, difference-in-differences study indicated that state mandates, which presumably lower the price of treating diabetes, were associated with higher body mass index.

Randomized experiments have also failed to find conclusive evidence. Findings from the Rand Health Insurance Experiment (RHIE), for instance, indicated that less generous health insurance did not have any significant or economically meaningful effect on health behaviors such as smoking, drinking, and exercise (Newhouse 1993; Bhattacharya et al. 2011). The Oregon Health Insurance Experiment (Baicker et al. 2013), which enrolled a group of uninsured low-income adults into Oregon's Medicaid program by lottery, found increased used of many preventive medical services, which likely reflects the lower cost of these services as a result of insurance. However, the study finds no statistically significant impacts on measures of primary prevention including the probability of being a current smoker and of being obese. The magnitude of the smoking effect, however, is relatively large (6 percentage points, $13 \%$ ), positive and suggestive of an increase in smoking prevalence subsequent to Medicaid coverage (pvalue marginally significant at 0.18 ).

Dave and Kaestner (2009) is the only study we are aware of that has tried to separate out the direct ex ante moral hazard effect of insurance from the indirect effects of health insurance on health behaviors operating through increased contact with healthcare professionals and shifts in health information and knowledge. Dave and Kaestner (2009) study the elderly and exploit the age eligibility of Medicare. The authors reported that after accounting for the effects of greater physician contact, obtaining 
Medicare was associated with a worsening of health behaviors, as measured by lower rates of smoking cessation, reduced physical activity and increased alcohol use.

In this study, we add to the relatively sparse literature on ex ante moral hazard, and extend the analysis of the effect of health insurance on health behaviors by examining the impact of Medicaid on the prenatal behaviors of pregnant women. In particular, we assess effects of Medicaid on maternal smoking and weight gain during pregnancy, and on behavior-related health indicators during pregnancy such as gestational diabetes, pregnancy-associated hypertension, and anemia. This represents the first national study of Medicaid effects on health behaviors among pregnant women.

We exploit the plausibly exogenous variation over time and between states in the Medicaid expansions in income-based eligibility for pregnant women that occurred during the late 1980s through the mid-1990s. Moreover, we account for the effect of insurance on health behaviors that works through greater contact with health care providers, and we assess heuristically whether an income effect can account for our findings.

\section{Conceptual Framework}

The model we use to examine the effect of Medicaid on health behaviors is based on the choices of a mother who cares about consumption, leisure, and child health. There are two periods that span the pre- to post-birth period. ${ }^{3}$ In this model, child health in the post-birth period is uncertain. With probability $(\pi)$, the child may experience an adverse health shock (z) that lowers child health and can be offset (repaired) with medical care $\left(\mathrm{m}_{1}\right)$. Medical care in the first period can also be used to alter the probability of an adverse health event in period two. ${ }^{4}$ First-period maternal consumption, for example, nutrition and smoking, may also affect the probability of an adverse health shock in period two. Health

\footnotetext{
${ }^{3}$ We assume that Medicaid has no effect on the pregnancy decision, which is consistent with some of the prior literature and which we confirm with our data (discussed in the text).

${ }^{4} \mathrm{We}$ do not treat medical care in the first period, for example maternal prenatal care, as uncertain and affected by insurance because such care is preventive and its effects are assumed known-i.e., there is no uncertainty. Including Medicaid coverage for maternal care prior to birth would not change any of the predictions described below.
} 
insurance is particularly important because it is used to buy medical care after the birth in the case of an adverse outcome.

A woman's expected utility is described by:

(1) $E(U)=u_{0}\left(x_{0}, l_{0}\right)+\beta\left\{\left[1-\pi\left(m_{0}, x_{0}\right)\right]\left[u_{1}\left(x_{1}, l_{1}, c\right)\right]+\pi\left(m_{0}, x_{0}\right)\left[u_{1}\left(x_{1}, l_{1}, c-z\left(m_{1}\right)\right)\right]\right\}$

Equation (1) reflects the fact that there are two periods: prior to birth $(\mathrm{t}=0)$ and after birth $(\mathrm{t}=1)$. Utility is a function of consumption (x), leisure (1) and child health (c) in each period, although in period 0 the child is not born and so child health does not enter the utility function. ${ }^{5}$ The discount rate is denoted by $(\beta)$.

The woman's budget constraint is given by:

(2) $x_{0}+p_{m} m_{0}+\frac{x_{1}}{1+r}+\pi\left(m_{0}\right) \frac{p_{m}(\alpha) m_{1}}{1+r}+\frac{f}{\alpha} \frac{1}{1+r}=w(\alpha)\left(1-l_{0}\right)+\frac{w(\alpha)\left(1-l_{1}\right)}{1+r}=W$

Lifetime income is spent on: consumption $(\mathrm{x})$ in periods 0 and 1 ; medical care $(\mathrm{m})$ in periods 0 and 1 with price of medical care denoted by $\mathrm{p}_{\mathrm{m}}$; and the quantity of health insurance $(\alpha)$ in period one. The interest rate is denoted by $(r)$. Health insurance reduces the price of medical care and is financed out of earnings (w). The cost of health insurance also includes a loading charge $(\mathrm{f} / \alpha)$ where $\mathrm{f}$ is a fixed cost of administering health insurance.

The constrained choice problem is given by:

$$
\begin{aligned}
L= & u_{0}\left(x_{0}, l_{0}\right)+\beta\left\{\left[1-\pi\left(m_{0}, x_{0}\right)\right]\left[u_{1}\left(x_{1}, l_{1}, c\right)\right]+\pi\left(m_{0}, x_{0}\right)\left[u_{1}\left(x_{1}, l_{1}, c-z\left(m_{1}\right)\right)\right]\right\} \\
& -\lambda\left[x_{0}+p_{m} m_{0}+\frac{x_{1}}{1+r}+\pi\left(m_{0}\right) \frac{p_{m}(\alpha) m_{1}}{1+r}+\frac{f}{\alpha} \frac{1}{1+r}-w\left(1-l_{0}\right)-\frac{w(\alpha)\left(1-l_{1}\right)}{1+r}\right.
\end{aligned}
$$

The first order condition for consumption in first period is given by ${ }^{6}$ :

(4)

$$
\begin{aligned}
& \frac{\partial L}{\partial x_{0}}=U_{x 0}-\beta \frac{\partial \pi}{\partial x_{0}}\left(\widetilde{u}_{1}-u_{1}\right)-\lambda\left[1+\frac{\partial \pi}{\partial x_{0}} \frac{p_{m}(\alpha) m_{1}}{1+r}\right]=0 \\
& U_{x 0}=\beta \frac{\partial \pi}{\partial x_{0}}\left(\widetilde{u}_{1}-u_{1}\right)+\lambda\left[1+\frac{\partial \pi}{\partial x_{0}} \frac{p_{m}(\alpha) m_{1}}{1+r}\right]
\end{aligned}
$$

\footnotetext{
${ }^{5} \mathrm{We}$ incorporate the demand for prenatal health by allowing first period medical care to influence the probability of an adverse event at birth.

${ }^{6}$ See Appendix for other first order conditions.
} 
Equation (4) is the usual equilibrium condition. The left hand side is the benefit of first period consumption and the right hand side is the cost, which includes the higher probability of lower second period utility because of an adverse health shock to child caused by first period consumption and the greater spending on second period medical care due to a higher probability of an adverse health shock $\left(\widetilde{u}_{1}\right.$ denotes period 1 utility if sick). ${ }^{7}$

Equation (4) also illustrates the problem of ex ante moral hazard. Health insurance $(\alpha)$ lowers the price of medical care, and a lower price of medical care reduces the cost of first period consumption that is related to the probability of a child health shock. With insurance, a mother has to incur less cost to treat (repair) an adverse event (for her or her child) associated with a birth. Therefore, health insurance may influence first period consumption that may adversely affect child health. Importantly, for Medicaid, there is no cost of insurance so the ex ante moral hazard problem is not eliminated through changes in insurance premiums. Of course, there is also an income effect associated with the lower price of health insurance and Medicaid that may increase consumption.

Dave and Kaestner (2009) raise another issue that is relevant, but not explicit in equation (4), and that is the possibility that the greater use of medical care that comes with insurance may affect the information available about the effect of consumption on the probability of an adverse health shock to child. For example, Medicaid may be associated with greater prenatal care, and during these visits the physician may discuss health behaviors and the value of prevention that causes a mother to change behaviors.

The upshot of this theoretical discussion is that the net effect of Medicaid coverage for pregnant women and their children on prenatal preventive activities is a priori ambiguous. Gaining insurance is associated with: 1) the pure ex ante moral hazard effect, which will tend to worsen health behaviors; 2) an income effect that is likely to increase consumption including some goods that are unhealthy such as

\footnotetext{
${ }^{7}$ Here we analyze the case where consumption has a negative effect on infant health, but as noted, some forms of consumption may have beneficial effects.
} 
smoking; and 3) an "informational" effect that comes from the greater contact with the medical system induced by the lower price of medical care. The income effect may improve or worsen health behaviors.

One issue that requires elaboration is whether it is plausible that pregnant women will respond to gaining Medicaid by changing behaviors. We believe it is. First, we emphasize that the responses are on the margin and may entail relatively minor changes in behaviors such as smoking less instead of quitting smoking and changes in diet such as eating less nutritious foods, drinking a little more alcohol and not worrying about vitamin consumption as much. Second, there is substantial evidence that people respond to similar insurance incentives in contexts that cause severe health consequences. In the workers' compensation area, there is overwhelming evidence that workers are more likely to injure themselves including losing a limb and even dying when worker's compensation benefits increase (Ruser 1995, 1991; Kaestner and Carroll 1997; Fortin and Lanoie 2000). Similarly, there are a greater number of car accidents including fatalities when accident insurance becomes more generous (Chiappori 2000; Cohen and Dehejia 2004). Thus, it is plausible that pregnant mothers, particularly low-educated mothers most likely affected by Medicaid expansions who may underestimate the adverse consequences to their and their child's health from engaging more in less healthy actions, would change their behavior after obtaining health insurance.

\section{Research Design}

Our empirical analysis is motivated by the incentives described above for pregnant women to potentially change their behavior in response to Medicaid coverage. To assess this hypothesis, we exploit plausibly exogenous variation from the Medicaid income eligibility expansions for pregnant women during the late-1980s through mid-1990s. We use data from the vital statistics natality files for births occurring from 1989 through 1997, the period that spanned the largest expansions in Medicaid eligibility for pregnant women and children. ${ }^{8}$

\footnotetext{
${ }^{8}$ There was little expansion of Medicaid for pregnant women post 1996.
} 
The research design is a difference-in-differences approach focusing on the intention-to-treat effect of expanded Medicaid eligibility. For each type of health behavior, we estimate the following regression specification:

$$
H_{i k j t}=\alpha_{k j}+\theta_{k t}+\delta E L I G_{k j t}+X_{i k j t} \Gamma+Z_{j t} \Psi+G_{m j t} \Omega+\mu_{i k j t}
$$

In equation (7), $\mathrm{H}$ denotes a specific health behavior (smoking or weight gain) or outcome (gestational diabetes, hypertension, and anemia) for pregnant woman $i$ in state $j$ and year $t$. ELIG is the fraction of women in group $\mathrm{k}$, which is defined by race and age (18-24, 25-29, 30-34, 35-39), in state $j$ and year $t$ that are eligible for Medicaid. The vector X represents individual characteristics of the pregnant woman such as age, education, marital status, race/ethnicity, and interactions between race and education; and Z represents a vector of time-varying state-level confounding factors including the unemployment rate (contemporaneous and the one-year lag and lead) to capture economic conditions, state excise tax on cigarettes (in models for smoking), and the fraction of single males with incomes below $200 \%$ of the federal poverty line (FPL) with private insurance in state $j$ and year $t$ to capture trends in private insurance among the low-income population.

All specifications control for state $(\alpha)$ and year $(\theta)$ fixed effects to capture unobserved timeinvariant area heterogeneity and national trends, and we allow these trends to vary by the race and age categories used to define the fraction of eligible women (ELIG). In order to control for other time-varying state-level unobservable variables, we also include in all models the prevalence (or mean) of the specific health behavior in question for college-educated married (denoted by the subscript $m$ ) pregnant women between the ages of 25-39 $\left(G_{m}\right)$, who are generally not Medicaid eligible and thus would not be impacted by the policy shift, for state $j$ and year $t .{ }^{9}$ Standard errors are constructed allowing for dependence of the errors within state cells. The parameter of interest is $\delta$, which captures the reduced-form, marginal effect of the expansions in Medicaid eligibility on prenatal behaviors.

\footnotetext{
${ }^{9}$ Note that this does not amount to using college-educated married pregnant women as a direct comparison group since we are not constraining the coefficient to be one (as would be the case in a difference-in-differences context). We include this variable to control for time-varying, state-specific changes in the behaviors.
} 
The use of the fraction of women eligible for Medicaid in each state and year to measure Medicaid eligibility follows the innovation of Currie and Gruber (1996) and Cutler and Gruber (1996). The key to this measure is that it records the fraction of a fixed sample of women who would be eligible for Medicaid if they were pregnant and lived in each state in each year and avoids the endogenous relationship between Medicaid eligibility of an individual mother and her health and health behaviors. The variation in this measure of eligibility comes from program rules alone -- after adjusting for inflation and state fixed effects; the only way the percent eligible in this fixed sample changes is due to changes in the state eligibility rules. As documented in Currie and Gruber (1996), federal mandates during the late 1980s and early 1990s resulted in substantial increases for all states in the fraction of pregnant women and their children who would be eligible for Medicaid, though the magnitude of the increase varied widely according to initial eligibility limits and state options regarding whether to offer coverage beyond the federally mandated minimum eligibility increases. We describe the construction of the eligibility fraction below in the data section.

We modify the basic empirical model described above in several ways to address specific issues. First, in supplementary models we include state-specific time trends to adjust for the potential endogeneity of the Medicaid expansions stemming from the possibility that the magnitude of the expansion is correlated with trends in health behaviors. Note that these trends are in addition to other time-varying, state-specific controls in the model including the unemployment rate and health behaviors of college-educated married women. As we show later, adding state-specific trends has virtually no effect on estimates bolstering the plausibility of our research design.

Second, we limit the main analyses to low-educated, single mothers because this subgroup of the population is relatively more likely to be affected by the Medicaid eligibility expansions. Low-educated, single mothers have far higher Medicaid eligibility and take-up rates and experienced larger shifts in insurance coverage relative to those with more education or those who are married (Dave et al. 2011, 
2014). ${ }^{10}$ In the same spirit, and as a placebo test, we estimate the model using a sample of highereducated, married pregnant women since they are far less likely to be affected by the expansions in Medicaid eligibility. Here too results suggest a valid research design, as almost all estimates for this group are not statistically significant and small.

Third, we allow the eligibility measure to have non-linear effects, which may be likely given that higher levels of eligibility are affecting women and children at increasingly higher income levels and with increasingly higher rates of private insurance and lower rates of being uninsured. At higher levels of eligibility, part of the increase in public coverage reflects a crowd-out of private coverage (see Dubay and Kenney 1997; Gruber and Simon 2008; Dave et al. 2011). In this instance, there may be smaller effects on health behaviors because at higher levels of Medicaid eligibility, Medicaid take-up is associated with greater shifts from private to public insurance, in which case there should be minimal changes in ex-ante moral hazard, and smaller shifts from no insurance to insurance. On the other hand, shifts from private coverage to public coverage would also entail an income effect, and depending on the size of the income effect, changes in behaviors may be stronger or weaker at higher levels of Medicaid eligibility.

Fourth, we control for prenatal care visits and the adequacy of prenatal care in order to disentangle the direct ex ante moral hazard effect, which implies a reduction in healthy behaviors, from greater insurance-induced contact with the medical care community, which implies an increase in healthy behaviors, as shown in the theoretical framework above. In models that do not control for prenatal care, the estimated effect would conflate both of these counteracting effects.

\section{Data}

\subsection{Natality Files}

Our data come primarily from information on individual birth records from the Vital Statistics Natality Files. Detailed information on all individual births occurring in the 50 states and D.C. are

\footnotetext{
${ }^{10}$ Medicaid participation among less-than-high-school educated pregnant women is 2.4 times greater relative to higher educated pregnant women, and 6.1 times greater among unmarried pregnant women relative to those who are married, based on the CPS.
} 
submitted by hospitals to state vital registration offices, which is then reported to the National Center for Health Statistics (NCHS). Information on each birth includes date and place of birth along with the demographic characteristics of the mother such as age, race, education, marital status, and parity. We employ natality data for the years 1989 through 1997, covering pregnancies which started from 1988 through 1996, as this period enveloped some of the major Medicaid income eligibility expansions that took place and because earlier years did not contain information on certain prenatal behaviors. The primary sample is limited to women with a high-school degree or less between the ages of 18 to 39 (at time of pregnancy). This yields up to 18.6 million births for the main analytical sample. We also conduct analyses using a sample of higher-educated married women contributing up to 6.3 million births.

We measure two categories of health behaviors: 1) three measures of prenatal smoking (prenatal smoking participation, smoking more than 5 cigarettes daily on average, smoking more than 10 cigarettes daily on average); and 2) weight gain during pregnancy. ${ }^{11}$ Birth certificates are generally thought to provide a reasonably reliable source of data on prenatal smoking status for large observational studies (Nielsen et al., 2014), although underreporting of smoking status has been suggested for as much as one fifth of smokers (Tong et al, 2013). While underreporting can inflate our variance estimates, there is no a priori indication that it is systematically correlated with the Medicaid expansions in a way that necessarily biases our estimates of the eligibility expansion effects, conditional on state and time fixed effects and the other controls in our models.

The weight gain outcome captures decisions related to nutrition, caloric intake, and physical activity. Between 1970 and 1990, guidelines recommended a weight-gain of 20-25 pounds during pregnancy, for normal-weight mothers, to ensure adequate caloric intake and a healthy normal-weight infant (Institute of Medicine 2009). Revised guidelines in 1990 called for even greater weight-gain for some groups (25-35 pounds for pregnant women with normal pre-pregnancy body mass index, for

\footnotetext{
${ }^{11}$ These outcomes are not reported by some states (for instance, CA, IN, NY, SD, OK) over all or part of our sample period. We exclude births occurring in these states when analyzing these behaviors.
} 
instance). ${ }^{12}$ Since we cannot observe pre-pregnancy weight in the natality data over our sample period, we employ the two thresholds of weight gain that no one is recommended to fall outside regardless of their weight gain during the study period, which would be 15-40 pounds, and also consider weight gain thresholds of 20-35 pounds.

We also used three maternal health indicators during pregnancy that are related to health behaviors such as nutrition and physical activity. These are gestational diabetes ${ }^{13}$, anemia, and hypertension. While gestational diabetes is not explained by behaviors in many cases, its risk increases with being overweight/obese and with poor management of pre-pregnancy and prenatal blood sugar levels (at prediabetic-levels), which are linked to diet and physical activity. Furthermore, management of gestational diabetes involves modification of diet (e.g. meal spacing), reduced sugar intake, monitoring blood sugar before meals, exercise, and weight gain monitoring and control. Similarly, hypertension risk during pregnancy is increased by unhealthy diets (e.g. consumption of salty/fatty foods and caffeine), overweight/obesity, low/no exercise, smoking, and alcohol consumption. Anemia can be prevented or treated by consuming iron and folate containing supplements and by eating iron and folate rich foods such as spinach and meat. We construct an indicator for whether a mother had any of these three conditions because the prevalence of any one condition was relatively low and therefore an analysis of individual conditions was underpowered.

We utilize two measures of prenatal care to account for effects of health insurance on health information through doctor contacts. The first captures the total number of prenatal care visits over the pregnancy period. The second is a measure of the adequacy of prenatal care based on the Kotelchuck adequacy criteria, which combines the timing of prenatal care initiation with the recommended number of visits adjusted for gestation. Specifically, a woman is considered to receive adequate prenatal care if she

\footnotetext{
${ }^{12}$ These guidelines were revised in 2009, in reflection of the obesity epidemic, for pre-pregnancy obese women, recommending their pregnancy-related weight gain to be limited to 11-20 pounds. The premise was that heavier women could gain less weight and still deliver a normal-weight infant.

${ }^{13}$ Prior to states using revised birth certificates starting in 2003, the data did not differentiate between pre-pregnancy and gestational diabetes. However, based on disaggregated data, almost $90 \%$ of these diabetes cases represent gestational diabetes.
} 
initiated care by the end of the $4^{\text {th }}$ month of her pregnancy and received at least $80 \%$ of the recommended number of visits during the time between initiation and delivery (Kotelchuck 1994).

Using the birth records from 1989-1997, we impute the year of pregnancy inception based on birth year and gestational age to identify pregnancies that were started between 1988 and 1996. We match Medicaid eligibility to the birth records by state, age group, race, and year of pregnancy. ${ }^{14}$ All other timevarying state variables are matched based on state and year of pregnancy.

\section{2. $C P S$}

To form the Medicaid eligibility measure, we selected a fixed state-specific sample of women aged 18 to 39 from the 1989 to 1997 March Current Population Surveys (CPS) (covering data from 19881996). We adjusted all financial variables for price changes such that incomes are deflated (inflated) from the actual year (e.g., 1988,..,1996) to the policy year (e.g., 1991) for which eligibility will be calculated. Using the "inflation-adjusted" sample and the Medicaid eligibility rules in a state in a specific year, we assigned eligibility to the (fixed) state sample so that eligibility is calculated using the same sample of women in each year for a given state. We then calculated the proportion of women aged 18 to 39 within a race-age-state-year cell that would be eligible for Medicaid if they became pregnant. ${ }^{15}$ From the CPS, we also calculate the fraction of single males with income below $200 \%$ of the FPL who are privately insured in each state/year from the CPS and include that as a covariate.

\footnotetext{
${ }^{14}$ We match Medicaid eligibility based on year of pregnancy for those records where gestation straddles adjacent years. This choice was motivated by evidence that prenatal smoking is most responsive during the first trimester (Colman, Grossman, and Joyce 2003; Colman and Joyce 2003). Alternately we imputed pregnancy year based on birth year and a standard gestation of 38 weeks for all births. Results are not sensitive to using this alternate measure.

${ }^{15}$ We chose to define the group cells for Medicaid eligibility by race and age (in addition to state and year) because of the large racial and age-related differences that exist in insurance coverage and health behaviors. Furthermore, the race- and age-specific samples exploit differences in the income distribution across these factors. If there is a different distribution of income by race, then that variation helps identify the association between Medicaid eligibility and outcomes and results in more precise estimates. For instance, a given shift in federal poverty line (FPL)-based eligibility in a specific state may lead to differential shifts for different races due to differences in racespecific and age-specific income distributions. Thus, Medicaid eligibility constructed for race- and age-specific samples provides a measure of the policy instrument with greater and more accurate variation when matched to individual records, which raises the precision of estimates.
} 


\subsection{Sample Description}

Table 1 presents means for the baseline period (all births occurring in 1989) for subgroups based on maternal marital status and education. The prevalence of prenatal smoking is $40.2 \%$ among loweducated (below high school) unmarried mothers, compared to $4.6 \%$ among college-educated married mothers. On average, weight gain among higher-educated, married mothers is about two pounds more than for lower-educated mothers (30.7 versus 28.5 pounds). Higher-educated, married mothers are also more likely to receive adequate prenatal care ( $88 \%$ versus $38 \%)$ and to have almost 4 more prenatal visits (average of 12.3 versus 8.4 visits) relative to lower-educated unmarried mothers. All of these differences are statistically significant. On average, $28.3 \%$ of pregnant women were eligible for Medicaid coverage over 1988-1996; among low-educated (high school graduate or less) women, this eligibility increased from $22 \%$ in 1988 to over 35\% by 1996 (see Figure 2). We exploit these expansions across states and over time to assess how public insurance coverage may impact low-educated pregnant women's prenatal behaviors.

\section{Results}

\subsection{Estimates for Low-educated Mothers}

Table 2 presents estimates of the reduced-form effect of expanding Medicaid eligibility for pregnant women on prenatal smoking, pregnancy weight gain, and behavior-related health indicators of low-educated (high school graduate or less) pregnant women. For each health behavior, we estimate models without and with state-specific linear trends. Results are virtually the same, so we present only those without state-specific trends in the text and include estimates with state-specific trends in Appendix Table A1. It is reassuring that the direction and magnitudes of the estimates are not at all sensitive to these controls, supporting the validity of the research design. ${ }^{16}$

Starting with Panel A, which reports linear effects of eligibility, models in columns 1-3 suggest that Medicaid eligibility is positively associated with smoking. Specifically, estimates indicate that a 13

\footnotetext{
${ }^{16}$ Estimates are also similar if we use state-specific quadratic trends (results available upon request).
} 
percentage-points increase in Medicaid eligibility, which is the approximate change that occurred over 1988-1996, is associated with a 0.7 percentage-point increase in the probability of prenatal smoking and a 0.6 percentage-point increase in the probability of smoking more than 5 cigarettes daily. These effects are statistically significant, and the magnitudes represent approximately a 3\% increase relative to the baseline mean smoking rates. ${ }^{17}$ Examining other margins indicate that there is also a smaller (1.8\%) increase in the probability of smoking greater than 10 cigarettes daily. All models for smoking control for the state excise tax on cigarettes, and show significant negative effects of taxes on prenatal smoking and magnitudes are consistent with the literature (Colman, Grossman, and Joyce 2003). ${ }^{18}$

Columns 4-8 present results for weight gain during pregnancy. The estimate in column 4 indicates that a 13 percentage-points increase in Medicaid eligibility is associated with a 0.12 pound decrease in weight gain. This estimate translates to a $0.5 \%$ decline relative to the baseline mean for loweducated mothers. The expansions also appear to be associated with a leftward shift of the weight-gain distribution, as evidenced by the increase in the prevalence of women who are gaining below the minimum recommended threshold (e.g., 15 pounds) and a significant decrease in the prevalence of women gaining above the maximum recommended threshold (35 pounds).

Estimates in column 9 suggest a small, but statistically insignificant increase in behavior-related adverse prenatal health indicators. A 13 percentage point increase in Medicaid eligibility is associated with approximately a $1.2 \%$ increase in the indicator for any of the three evaluated gestational health problems. ${ }^{19}$

Panel B of Table 2 reports models that assess whether there are non-linear effects of Medicaid eligibility. Given that higher levels of eligibility are affecting individuals with increasingly higher income

\footnotetext{
${ }^{17}$ The increase in prenatal smoking may reflect a decrease in quitting among women who smoked prior to pregnancy and/or an increase in initiation. However, it is unlikely that results are driven by initiation. The majority of smokers initiate smoking prior to age 18, and virtually all initiate prior to age 21 . Our results are robust to excluding pregnant women ages 18-20. Furthermore, very few women start smoking during pregnancy.

${ }^{18}$ The tax elasticity for prenatal smoking among pregnant women with a high education or below is -0.05 .

${ }^{19}$ In models for the individual gestational health indicators, all effects are positive though insignificant, and effect sizes associated with a 13 percentage-points increase in Medicaid eligibility range from about 1-3\%.
} 
and rates of private insurance, and lower rates of no insurance, one might expect Medicaid expansions at high levels of eligibility to have smaller effects, as much of the change in insurance is in type of coverage rather than individuals becoming newly insured (Dubay and Kenney 1997; Dave et al. 2011). However, even changes from private to public insurance entail an income effect, which may be even larger for those who shift from private to public coverage versus those shifting from no coverage (Merlis 2002; also see footnote 22). Furthermore, there may still be some shifts in incentives due to differences in cost-sharing, provider access, and other components between private insurance and Medicaid. Therefore, a priori it is uncertain whether effects on behaviors would diminish or strengthen with expansions in eligibility. We allow for non-linear effects of Medicaid eligibility using a dummy variable specification for different categories of the proportion of the sample that are eligible: $20-29 \%, 30-49 \%, 50 \%$ or more (reference category: eligibility $<20 \%)^{20}$

For smoking, estimates in Panel B of Table 2 indicate that expansions in Medicaid eligibility up to $50 \%$ of the sample are positively associated with prenatal smoking with a slightly larger effect than implied by the linear specification in Panel A. For example, the estimate in Panel A suggests that a 25 percentage-points and 40 percentage-points increase in Medicaid eligibility are associated with a 1.4 and 2.3 percentage points increase in smoking, respectively. In Panel B, analogous estimates are 2.9 and 4.1 percentage points, respectively. Panel B estimates indicate that there is some concavity in the association between Medicaid eligibility and prenatal smoking. The non-linear association is underscored by the notable difference between estimates in Panel A and Panel B for the highest eligibility category. These estimates indicate that at high levels of eligibility, there is no effect of eligibility on smoking, which is consistent with the likely smaller change in health insurance status (i.e., treatment) at that level of eligibility, although there may be heterogeneous effects by income and other characteristics too. Also, in 1996 , less than $15 \%$ of pregnant women lived in states where eligibility was $50 \%$ or more, so estimates for the other categories are most applicable.

\footnotetext{
${ }^{20}$ Estimates and patterns are similar if we alternately employ indicators for eligibility quintiles.
} 
Estimates in Panel B of Table 2 for weight-gain are somewhat more complex and quite different from estimates in panel A. In Panel B, estimates indicate that increases in Medicaid eligibility up to 50\% of the sample are associated with an increase in weight gain and a rightward shift in the weight distribution, although effect sizes are small. For example, the estimate pertaining to the $20 \%-30 \%$ eligibility category in the case of weight gain greater than 35 pounds is 0.006 , or $2 \%$ of the mean. In contrast, high levels of Medicaid eligibility — greater than 50\% of the sample—are associated with a decrease in weight gain and a leftward shift in weight gain distribution, but again estimates are quite small.

With respect to the gestational health indicator, estimates in Panel B are small, positive and mostly not statistically significant. However, the estimates suggest a plateauing of effects where the initial increase in eligibility is associated with a small, positive increase in the prevalence of these healthbehavior indicators, but further increases in eligibility do not alter that effect. The small magnitude of the estimates, however, warrants caution with respect to drawing firm inferences.

\subsection{Estimates for Less-than-High School Educated Single Mothers}

Estimates in Table 2 were obtained using a sample of pregnant women with at most a high school education. Among this group, it was predominantly the lowest-educated single mothers who experienced the highest Medicaid take-up rates and the largest changes in insurance coverage, and were therefore relatively more likely to be affected by the Medicaid eligibility expansions. Accordingly, we re-estimated models using a sample of mothers with less-than-high school educated single mothers. Estimates using this sample are presented in Table 3. Assuming a similar behavioral response, we expect the intention-totreat estimates in Table 3 to be generally larger than those in Table 2 because of the larger "first stage" effect on coverage. ${ }^{21}$

We begin the discussion with estimates in Panel A based on the linear specification of eligibility. For smoking, estimates in columns 1 through 3 of Table 3 are approximately the same magnitude as the

\footnotetext{
${ }^{21}$ It should be noted that differential effects are possible and may reflect heterogeneity in the behavioral response across the education distribution even if Medicaid take-up rates are similar.
} 
comparable estimates in Table 2, but they are not statistically significant because of the large drop in sample size. A 13 percentage-points increase in eligibility raises prenatal smoking and the probability of smoking more than 5 cigarettes by about 0.7 percentage points. For weight gain, however, estimates in Table 3 are somewhat larger than corresponding estimates in Table 2. A 13 percentage-points increase in Medicaid eligibility is associated with a 0.18 pound decrease in weight gain $(0.6 \%)$, a 0.3 percentagepoint increase $(2.5 \%)$ in the probability of gaining less than 15 pounds, and a 0.5 percentage-point decrease in the probability of gaining more than 35 pounds $(2 \%)$. The estimate for health conditions is close to Table 2 and not statistically significant. Estimates in Panel B of Table 3 are largely similar to estimates in Panel B of Table 2 and do not merit extensive comment, with the main exception that effects on gaining more than 35 or 40 pounds are smaller and insignificant for eligibility above $50 \%$ unlike in Table 2 .

\subsection{Adjusting for Prenatal Care}

Estimates presented so far capture the reduced-form effect of the eligibility expansions for pregnant women on their health behaviors, which operates through a potential ex ante moral hazard channel, an income effect, and through insurance-induced contact with physicians. To try to distinguish between these channels, we re-estimated models controlling for the adequacy of prenatal care and the number of prenatal care visits over the pregnancy in the main sample of low-educated mothers. Estimates are shown in Table 4.

Estimates in Table 4 are virtually unchanged from those in Table 2, which do not control for the measures of prenatal care. The implication of the results presented in Table 4 is that insurance-induced prenatal care and greater contact with healthcare professionals is not a confounding influence and that the effects we observe are likely due to the income and ex ante moral hazard mechanisms. Similar results are found when limiting the sample to single mothers who have not graduated from high school. ${ }^{22}$

\footnotetext{
22 This contrasts with the study by Dave and Kaestner (2009), who find that insurance improves health behaviors through greater physician contact. Part of the reason why there may not be strong counteracting effects in our case relates to the difference in study populations. Dave and Kaestner (2009) investigate the effects of Medicare and their population of interest is the elderly upon receiving public insurance at age 65 , whereas we study the Medicaid-
} 
While controlling for potential confounding factors (in this case, prenatal care) is a common practice, Angrist and Pischke (2009) note that including such "mediators" in the specification is problematic because these mediators are themselves endogenous, and hence would lead to biased estimates. In this case, estimates barely change with the addition of prenatal care suggesting that any bias is small, but as an alternative, we also directly estimated the effect of the eligibility expansions on the joint probability between the various health behaviors and measures of prenatal care adequacy using multinomial logit models (MNL). The marginal changes in these joint probabilities allow us to pick up potential interactions between these behaviors and contact with the medical profession, and assess both unconditional and conditional (on prenatal care) effects of the eligibility expansions on prenatal behaviors. These results (not presented) are qualitatively and quantitatively the same as those presented in Table $4 .^{23}$ Hence, our results do not indicate that prenatal care had any meaningful effects on the outcomes we evaluate.

\subsection{Additional Specification Checks}

The Medicaid expansions were targeted at low-income women and, therefore, college-educated, married mothers were largely unaffected. Accordingly we re-estimated models using a sample of college-

\footnotetext{
eligible population of low-educated single mothers ages 18-39. For instance, Dave et al. (2008) study the direct effects of these expansions on prenatal care and find that a 20 percentage-points increase in eligibility is associated with an insignificant 0.06 additional prenatal visit, about half a percentage point increase (also statistically insignificant) in the probability of receiving adequate care, and a significant 0.3 percentage point decrease in late ( $3^{\text {rd }}$ trimester) prenatal care initiation, among low-educated mothers. Hence, it does not appear that the expansions resulted in significantly higher contact between pregnant women and the medical care community, at least for the average mother, which may explain why the results are not sensitive to controlling for prenatal care.

${ }^{23}$ Specifically, we assessed movement of the probability density across four categories comprising combinations of adequate prenatal care and prenatal smoking (1: $1^{\text {st }}$ trimester care + No smoking; $2: 1^{\text {st }}$ trimester care + Smoking; 3 : No $1^{\text {st }}$ trimester care + No smoking; 4 : No $1^{\text {st }}$ trimester care + Smoking), and similar combinations of adequate prenatal care and weigh gain thresholds. With respect to smoking, the marginal effect suggest an increase in the joint probability of prenatal care and smoking (category 2) and the probability of prenatal care and no smoking (category 1) relative to the other two categories - thus an increase in early initiation, conditional on smoking. A 12 percentagepoints increase in eligibility would move about $1.5 \%$ late initiators into early care, based on the MNL estimates. We also find that the expansions are associated with an increase in the probability of prenatal care and smoking (category 2) and the probability of no prenatal care and smoking (category 4) relative to the other two categories; thus Medicaid is associated with an overall increase in prenatal smoking (and, of more than 5 cigarettes daily), and it is validating that these effect magnitudes are highly similar to the OLS estimates ( 0.07 and 0.1$)$ in Tables 2 and 3 for the two sub-populations. Turning to the MNL models that assess non-linear effects of eligibility, we find as before that the patterns and effect magnitudes diminish at higher levels of eligibility. MNL estimates are not reported, and results are available from the authors upon request.
} 
educated, married mothers to assess whether we find null effects consistent with the absence of treatment for this group. Estimates are presented in Table 5. Notably, we do not find any economically meaningful or statistically significant effects of the expansions on their prenatal smoking or weight gain behaviors. ${ }^{24}$ Estimates in Table 5 adds to other evidence, for example, the lack of sensitivity of estimates to the inclusion of state-trends, supporting the research design and bolsters the plausibility of our approach.

One concern for our research design is that Medicaid eligibility expansions changed the composition of our sample, which is limited to low-educated mothers, and in some analyses, unmarried, low-educated mothers. If Medicaid eligibility expansions affected fertility or marital status, then the composition of our sample would be changing along with Medicaid eligibility and our estimates of the effect of eligibility on maternal behaviors would include this sample selection effect. To assess whether there were changes in the composition of our sample, we estimated a regression model identical to that used to analyze maternal behaviors using an indicator for the probability of being in our sample. Specifically, the dependent variable was equal to one if a birth was to a low-educated (and unmarried) mother and zero otherwise. Estimates of the coefficient on Medicaid eligibility from this model were small (ranging from 0.004 to 0.039 associated with a $100 \%$ change in eligibility) and statistically insignificant (p-values from 0.429 to 0.464 ). These results suggest that any changes in the composition of mothers were not systematically associated with the Medicaid eligibility expansions, which is consistent with the analyses of DeLeire et al. (2011) and Zavodny and Bitler (2010) who examine directly whether Medicaid expansions had any effect on fertility and abortion..$^{25}$

\section{Discussion}

Assessing the effects of the Medicaid program on health behaviors is important since state and federal governments have dramatically expanded Medicaid over the past two decades to provide

\footnotetext{
${ }^{24}$ The low prevalence of smoking for this group limits the statistical power of this falsification test.

${ }^{25}$ In contrast, Joyce et al. (1998), using pooled cross-sections of states, find that expansions in the income thresholds for Medicaid eligibility between 1987 and 1991 are associated with a 5\% increase in the birthrate among white women, but not among black women.
} 
insurance for an increasingly large proportion of poor and near-poor persons. It is a particularly important objective in the case of pregnant women because of the known influence of prenatal health on adult outcomes. The rationale for these expansions is to decrease the population that is uninsured, and consequently to increase the use of healthcare services and improve population health. However, besides anticipated effects on health services use, insurance coverage expansions may also result in meaningful unintended changes in health behavior, some of which reflect a worsening in primary prevention effort and an increase in risky behaviors. No previous research has directly evaluated the effect of Medicaid on behaviors among pregnant women. We provide the first such evaluation based on quasi-experimental variation in Medicaid expansions between states and over time in the late 1980s through mid-1990s.

Economic theory suggests three main effects of gaining health insurance coverage on health behaviors. One effect is a reduction in primary prevention activities because insurance reduces the price of curative medical care and therefore lowers the financial costs of illness (ex ante moral hazard). Another effect is from greater income because of reduced out-of-pocket expenditures. Finally, insurance could alter health behaviors through greater contact with health providers.

We find consistent evidence that Medicaid expansions were associated with an increase in prenatal smoking and a change in pregnancy weight gain for low-educated mothers. These effects are found whether we account for increases in prenatal care services or not suggesting no/little indirect effect of insurance on health behaviors because of increased contact with prenatal care providers.

Specifically, an increase in Medicaid eligibility of 13 percentage points for pregnant women (approximately the magnitude of the expansion over the sample period) raised the likelihood of smoking during pregnancy by approximately 0.7 percentage point or $3 \%$ relative to the baseline mean. This is an average effect that masks considerable heterogeneity over the eligibility distribution with no evidence of an effect above $50 \%$ eligibility. Observing no effect on smoking at high-levels of eligibility is consistent with, among other explanations, a smaller change in insurance coverage for higher income mothers who are affected at that level of eligibility. 
We note that these effects are intention-to-treat (ITT) effects since Medicaid take-up rates are typically far less than $100 \%$. To obtain a sense of what the treatment-on-treated (TOT) effect may be, we assume a Medicaid take-up rate of 50\% (25\%). Accordingly, the ITT estimate noted earlier (for a 13 percentage-points change in eligibility) needs to be scaled upwards by a factor of 15 (31) in order to derive the structural TOT estimate of gaining Medicaid coverage. Doing so implies that gaining Medicaid coverage for a low-educated mother who was previously uninsured raised the likelihood of prenatal smoking by approximately 11 (22) percentage points, or approximately $40 \%(82 \%)$ of the 1989 baseline prevalence among low-educated mothers. Implicit TOT effects rescaled in this manner should be interpreted with caution because small changes in the denominator (in this case the Medicaid take-up rate) and the underlying estimates can lead to large differences. Nevertheless, our finding is consistent with Baicker et al. (2013), who find that randomly-assigned Medicaid eligibility in Oregon is associated with an increase in smoking of about 6 percentage points with a confidence interval ( -2.5 to 13.7 percentage points) that includes our back-of-the-envelope treatment-on-the-treated estimate.

The effects of Medicaid eligibility on smoking that we observe result from both ex ante moral hazard and income effects (as there is no evidence for an effect due to greater prenatal care). Reductions in out-of-pocket spending on healthcare as a result of Medicaid coverage will increase consumption of both risky and healthy behaviors. Gruber and Yelowitz (1999) find that expanding Medicaid eligibility for pregnant women and all children between 1984-1993 raised overall consumption expenditures, and Leininger et al. (2010) find similar increases in consumption spending due to the reduction in the family's out-of-pocket medical spending associated with expansions in the State Children's Health Insurance Program (SCHIP). 
On average, reduction in out-of-pocket spending with switching from uninsured to Medicaid coverage is $\$ 700,{ }^{26}$ which represents a $9 \%$ increase in income for women in our sample. ${ }^{27}$ Kenkel et al. (2014) estimate an income elasticity of smoking at the extensive margin of 3.6 among low-income adults. While this is clearly a large estimate, we use it to assess the maximum amount of the smoking effect that may be due to income. Combining these estimates suggests that the potential income effect associated with the Medicaid expansion would lead to an increase in smoking by as much as 8.7 percentage points (or 32\% of the baseline mean in this group). This compares to the imputed TOT estimate of 11 percentage points based on a Medicaid take-up rate of $50 \%$. So part of the increase in smoking, perhaps a large part of it, may be due to an income effect, but there likely remains an ex ante moral hazard effect too. Moreover, the potentially large income effect bolsters the plausibility of our estimate, which at first appears quite large. In fact, it is reasonable given the change in income and possible ex ante moral hazard effects.

We also find evidence that the expansions were associated with changes in pregnancy-related weight gain with marked non-linearity in the association. For modest expansions in eligibility, up to the point where $50 \%$ of the low-educated mothers are eligible, Medicaid eligibility is associated with small increases in pregnancy weight gain and rightward shift in the pregnancy weight gain distribution. However, we emphasize that the estimates are small (e.g., 2\% of mean effect size). At higher levels of eligibility, Medicaid eligibility is associated with a small decrease in weight gain. The implications of these findings for maternal and infant health are a priori unclear because guidelines recommend a weight gain of 25 to 35 pounds for a woman who is normal weight pre-pregnancy, but at the same time gaining too much weight during pregnancy, especially for pre-pregnant overweight or obese women, may be risky for the mother and the infant.

\footnotetext{
${ }^{26}$ These estimates are based on average out-of-pocket spending for non-Medicare Medicaid/publicly insured families with a health problem of $\$ 250$, compared to about $\$ 1100-1200$ with employer/other private coverage, and $\$ 550$ without coverage (Tables $6 \& 8$ of Merlis, 2002).

${ }^{27}$ Average annual personal income from all sources over the sample period was $\$ 7,650$ for low-educated pregnant women identified in the CPS.
} 
The results from this study suggest that the Medicaid eligibility expansions may have reduced prevention efforts of low-educated pregnant women and increased their participation in unhealthy behaviors, specifically smoking. These results highlight the importance of providing incentives to maintain prevention efforts, for instance by encouraging visits to the doctor, removing cost-sharing for preventive care, or capitalizing on the patient-physician contact to probe and encourage healthy behaviors, when designing public insurance program expansions in order to reduce unintended adverse behavioral effects. Most importantly, our results may explain why Medicaid expansions have not been associated with substantial improvement in infant health. 


\section{Appendix}

The first order condition for consumption in period 2 (post-birth) is given by:

(4) $\frac{\partial L}{\partial x_{1}}=\beta U_{x 1}=\lambda\left[\frac{1}{1+r}\right]$

This is the standard result: discounted marginal utility of consumption is equated to the discounted cost of consumption.

The first order conditions for medical care are given by:

$$
\begin{aligned}
& \frac{\partial L}{\partial m_{0}}=\beta \frac{\partial \pi}{\partial m_{0}}\left(\widetilde{u}_{1}-u_{1}\right)-\lambda\left[p_{m}(\alpha)+\frac{\partial \pi}{\partial m_{0}} \frac{p_{m}(\alpha) m_{1}}{1+r}\right]=0 \\
& \beta \frac{\partial \pi}{\partial m_{0}}\left(\widetilde{u}_{1}-u_{1}\right)=\lambda\left[p_{m}(\alpha)+\frac{\partial \pi}{\partial m_{0}} \frac{p_{m}(\alpha) m_{1}}{1+r}\right]
\end{aligned}
$$

(5)

$$
\begin{aligned}
& \frac{\partial L}{\partial m_{1}}=-\beta \pi \frac{\partial u_{1}}{\partial c} \frac{\partial z}{\partial m_{1}}-\lambda \pi \frac{p_{m}(\alpha)}{1+r}=0 \\
& -\beta \pi \frac{\partial u_{1}}{\partial c} \frac{\partial z}{\partial m_{1}}=\lambda \pi \frac{p_{m}(\alpha)}{1+r}
\end{aligned}
$$

First-period medical care is valued because it reduces the probability of an adverse event and raises expected utility in the second period ( $\widetilde{u}_{1}$ denotes period 1 utility if sick). A lower probability of an adverse event also reduces second-period medical expenditures. Both of these marginal benefits are equated to the price of medical care. Second-period medical care raises utility by improving child health and this marginal benefit is equated to the price of medical care.

The first order conditions for leisure are:
(6) $\frac{\partial L}{\partial l_{0}}=u_{0 l}-\lambda w=0$
$\frac{\partial L}{\partial l_{1}}=\beta u_{1 l}-\lambda \frac{w\left(\alpha_{1}\right)}{1+r}=0$
$u_{0 l}=\lambda w$
$u_{1 l}=\lambda w\left(\alpha_{1}\right) \quad[\beta(1+r)=1]$

A woman trades leisure for work (consumption) according to the wage.

The first order condition for health insurance is: 
(7)

$$
\begin{aligned}
& \frac{\partial L}{\partial \alpha}=-\lambda\left[\pi \frac{\partial p_{m}}{\partial \alpha} \frac{m_{1}}{1+r}-\frac{f}{\alpha^{2}} \frac{1}{1+r}-\frac{\partial w}{\partial \alpha} \frac{\left(1-l_{1}\right)}{1+r}\right]=0 \\
& -\pi \frac{\partial p_{m}}{\partial \alpha} \frac{m_{1}}{1+r}=\frac{f}{\alpha^{2}} \frac{1}{1+r}-\frac{\partial w}{\partial \alpha} \frac{\left(1-l_{1}\right)}{1+r}
\end{aligned}
$$

According to (7), a woman chooses insurance to equate the expected medical expenditures to the cost of insurance, which is the wage offset plus loading cost. Again, the expansion of Medicaid makes insurance free and there is an income effect associated with this change. The income effect may also be driven by Medicaid-induced shifts in labor supply. Dave et al. (2015) find that Medicaid expansions for pregnant women led to a decrease in their employment and labor force participation. Additionally, there are no changes in premiums to reflect the behavioral responses of Medicaid beneficiaries to the price change of medical care. 


\section{References}

Almond D, Currie J. 2011. Killing Me Softly: The Fetal Origins Hypothesis. Journal of Economic Perspectives 25(3): 153-72

Angrist, Joshua D., and Jorn-Steffen Pischke. Mostly Harmless Econometrics: An Empiricist's Companion. Princeton and Oxford:, 2009.

Baicker, Katherine, Amy Finkelstein, Jae Song, and Sarah Taubman. 2013. "The Impact of Medicaid on Labor Force Activity and Program Participation: Evidence from the Oregon Health Insurance Experiment." Cambridge, MA: National Bureau of Economic Research Working Paper \# 19547.

Bhattacharya, J., M. K. Bundorf, N. Pace, and N. Sood. 2011. "Does Health Insurance make you Fat?" in Michael Grossman and Naci Mocan (Eds.), Economic Aspects of Obesity, p. 35-64, University of Chicago Press.

Card, D., Dobkin, C., \& Maestas, N. (2008). The impact of nearly universal insurance coverage on health care utilization and health: Evidence from Medicare. The American Economic Review, 98(5), 2242-2258.

Centers for Disease Control and Prevention. 2002. Infant mortality and low birth weight among black and white infants - United States, 1980 - 2000. Morbidity and Mortality Weekly Report 51(27): 589- 592.

Chiappori, P. A. (2000). Econometric models of insurance under asymmetric information. In G. Dionne (Ed.), Handbook of Insurance. North Holland

Cohen, A., \& Dehejia, R. (2004). The effect of automobile insurance and accident liability laws on traffic fatalities. The Journal of Law \& Economics, 47(2), 357-393. doi:10.1086/422978.

Colman, G. J., \& Joyce, T. (2003). Trends in smoking before, during, and after pregnancy in ten states [PRAMS]. American Journal of Preventive Medicine, 24, 29-35.

Colman, Greg, Michael Grossman, and Ted Joyce, 2003, The effect of cigarette excise taxes on smoking before, during, and after pregnancy, Journal of Health Economics 22, 1053-1072.

Courbage, C., \& Coulon, A. (2004). Prevention and private health insurance in the U.K. Geneva Papers on Risk and Insurance: Issues and Practice, 29(4), 719-727. doi:10.1111/j.1468-0440.2004.00313.x

Currie J. 2009. Healthy, Wealthy, and Wise: Socioeconomic Status, Poor Health in Childhood, and Human Capital Development., Journal of Economic Literature, 47(1):87-122.

Currie, J., \& Gruber, J. (1996). Saving babies: The efficacy and cost of recent changes in the Medicaid eligibility of pregnant women. The Journal of Political Economy, 104(6), 1263-1296.

doi:10.1086/262059.

Curtin, S.C., M. Osterman, S.F. Uddin, S.R. Sutton, and P.R. Reed. (2013) "Source of Payment for the Delivery: Births in a 33-state and District of Columbia Reporting Area, 2010," National Vital Statistics Report, 62(5): 1-20.

Currie J, and J Gruber. 1996. Health insurance eligibility, utilization of medical care, and child health. The Quarterly Journal of Economics 111: 431-466. 
Cutler, D. M., \& Zeckhauser, R. (2000). Insurance markets and adverse selection. In A. J. Cutler \& J. P. Newhouse (Eds.), Handbook of health economics. North Holland.

Dave, D., and R. Kaestner. 2009. Health Insurance and Ex Ante Moral Hazard: Evidence from Medicare. International Journal of Health Care Finance and Economics. Published online March 11, 2009. DOI 10.1007/s 10754-009 9056-4.

Dave, Dhaval, Sandra L. Decker, Robert Kaestner, and Kosali I. Simon. 2008. "Re-examining the Effects of Medicaid Expansions for Pregnant Women" National Bureau of Economic Research Working Paper Series, No. 14591.

Dave, Dhaval, Sandra L. Decker, Robert Kaestner, and Kosali I. Simon. 2011. "The Effect of Medicaid Expansions on Health Insurance Coverage of Pregnant Women: An Analysis Using Deliveries." Inquiry 47:315-330.

Dave, Dhaval, Sandra L. Decker, Robert Kaestner, and Kosali I. Simon. 2014. "The Effect of Medicaid Expansions in the Late 1980s and Early 1990s on the Labor Supply of Pregnant Women" American Journal of Health Economics, 1(2): 165-193.

DeLeire, Thomas, Leonard M. Lopoo, and Kosali I. Simon. 2011. "Medicaid Expansions and Fertility in the United States." Demography 48: 725-747.

Dubay, L., and G. Kenney. 1997. Did the Medicaid expansions for pregnant women crowd-out private insurance?" Health Affairs 16(1): 185-193.

Fortin, B., \& Lanoie, P. (2000). Incentive effects of worker's compensation: A survey. In G. Dionne (Ed.), Handbook of insurance. North Holland.

Gruber, J., and K. Simon. 2008. Crowd-out ten years later: Have recent public insurance expansions crowded out private health insurance?" Journal of Health Economics 27: 201-217.

Gruber, J. and A. Yelowitz. "Public Health Insurance and Private Savings," Journal of Political Economy, 107(6): 1249-1274, 2009.

Hadley, J. 2003. Sicker and Poorer-The Consequences of Being Uninsured: A Review of the Research on the Relationship between Health Insurance, Medical Care Use, Health, Work, and Income. Medical Care Research and Review 60(2 Suppl):3S-75S.

Howell, E.M. 2001. The impact of the Medicaid expansions for pregnant women: A synthesis of the evidence. Medical Care Research and Review 58(1): 3-30.

Hoynes, H., D. Miller, and D. Simon. (2014) "Income, The Earned Income Tax Credit, and Infant Health," American Economic Journal: Economic Policy, Forthcoming.

Institute of Medicine. 2009. Weight Gain during Pregnancy: Reexamining the Guidelines, Report Brief, May 2009.

Joyce, Theodore, Robert Kaestner, and Florence Kwan. 1998. "Is Medicaid Pronatalist? The Effect of Eligibility Expansions on Abortions and Births.” Family Planning Perspectives 30: 108-113. 
Kaestner, R., \& Carroll, A. (1997). New estimates of the labor market effects of workers' compensation insurance. Southern Economic Journal, 63(3), 635-651. doi:10.2307/1061099.

Kelly, Inas Rashad; Markowitz, Sara. Incentives in Obesity and Health Insurance. Inquiry, 46(4): 418432, Winter 2009.

Kenkel, D. S. (2000). Prevention. In A. J. Culyer \& J. P. Newhouse (Eds.), Handbook of health economics. North Holland.

Kenkel, D.S., M.D. Schmeiser, and C.J. Urban. "Is Smoking Inferior? Evidence from Variation in the Earned Income Tax Credit," National Bureau of Economic Research Working Paper Series, No. 20097. May 2014.

Klick, J., and T. Stratmann. (2007). "Diabetes Treatments and Moral Hazard," Journal of Law and Economics, 50, p. 519.

Kotelchuck, M. (1994) "The Adequacy of Prenatal Care Utilization Index: Its US Distribution and Association with Low Birthweight," American Journal of Public Health, 84(9): 1486-1489.

Leininger L, Levy H, Schanzenbach D. Consequences of SCHIP Expansions for Household Well-Being. Forum for Health Economics \& Policy, 13(1):1-30, 2010

Levy, H., and D. Meltzer. 2004. What do we really know about whether health insurance affects health?" pp179-204 in C. McLaughlin ed. Health policy and the uninsured. Urban Institute Press, Washington D.C.

Lilliard, L. A., Manning, W. G., Peterson, C. E., Lurie, N., Goldberg, G., \& Phelps, C. E. (1986). Preventive medical care: Standards, usage and efficacy. Santa Monica, CA: Rand Publication Services, Report No. R3266-HCFA.

Merlis, M. (2002) "Family out-of-pocket spending for health services: a continuing source of financial insecurity," The Commonwealth Fund, www.cmwf.org.

Newhouse, J. P. (1993). Free for all? Lessons from the RAND health insurance experiment. In A RAND study. Cambridge, London: Harvard University Press

Nielsen, S.S., Dills, R.L., Glass, M., and Mueller, B.A. (2014) "Accuracy of prenatal smoking data from Washington State birth certificates in a population-based sample with cotinine measurements," Annals of Epidemiology, 24(3), 236-239.

Ruser, J. W. (1985). Workers' compensation insurance, experience-rating, and occupational injuries. The Rand Journal of Economics, 16(4), 487-503. doi:10.2307/2555508.

Ruser, J. W. (1991). Workers' compensation and occupational injuries and illnesses. Journal of Labor Economics, 9(4), 325-350. doi:10.1086/298272.

Stanciole, A. E. (2008). Health insurance and life style choices: Identifying the ex-ante moral hazard. The Geneva Papers, 33, 627-644. 
Tong, V.T., Dietz, P.M., Farr, S.L., D’Angelo, D.V., and England, L.J. (2013) “Estimates of smoking before and during pregnancy, and smoking cessation during pregnancy: comparing two population-based data sources," Public Health Reports, 128(3), 179-88.

Zavodny, Madeline and Marianne Bitler. 2010. "The Effect of Medicaid Eligibility Expansions on Fertility.” Social Science and Medicine 71: 918-924. 
Figure 1

Percent Low Birth Weight and Percent Preterm 1990 to 2010 by Race/Ethnicity \& Education

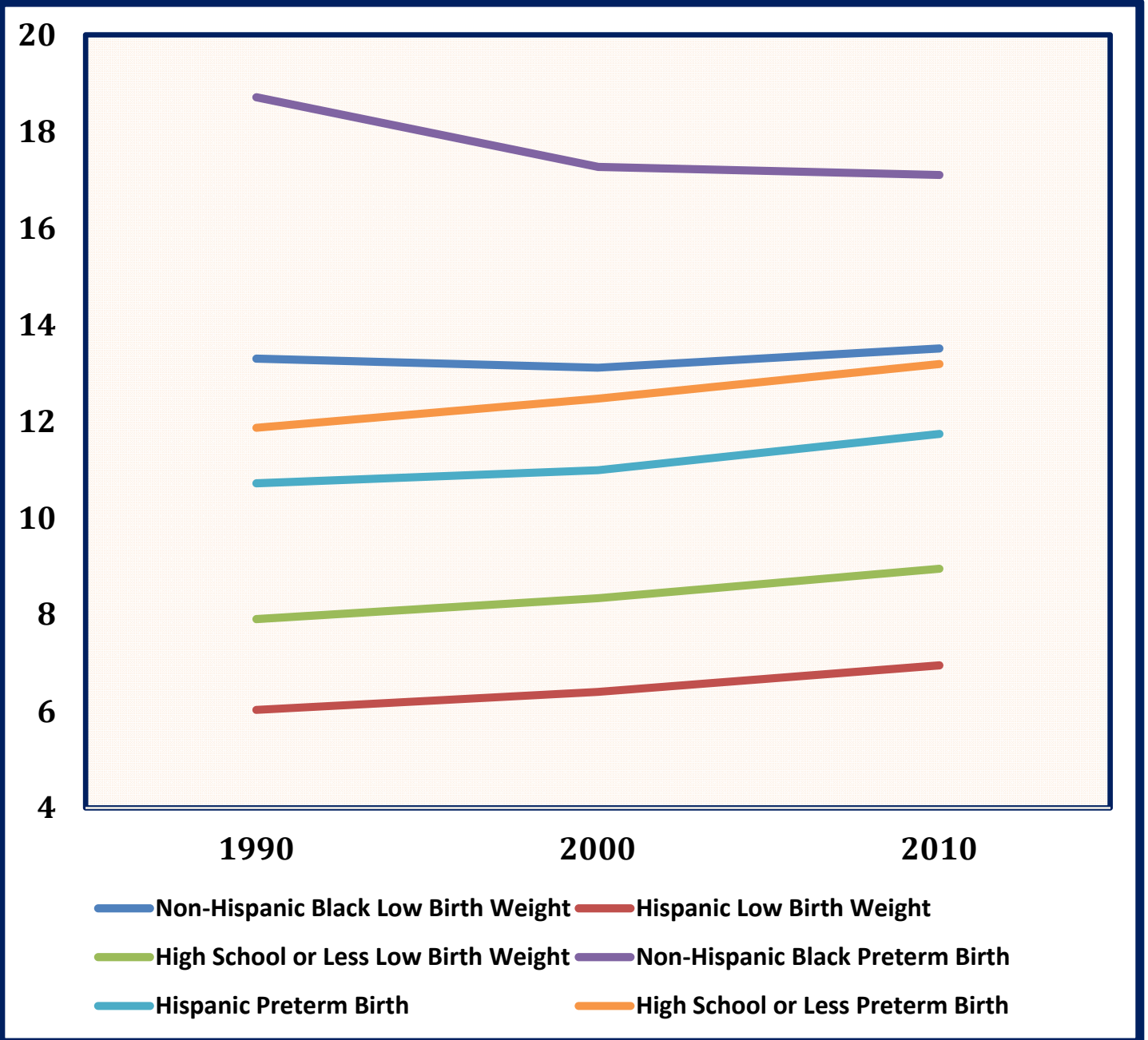


Figure 2

Fraction of Pregnant Women Eligible for Medicaid Coverage

Natality Files: 1988 - 1996

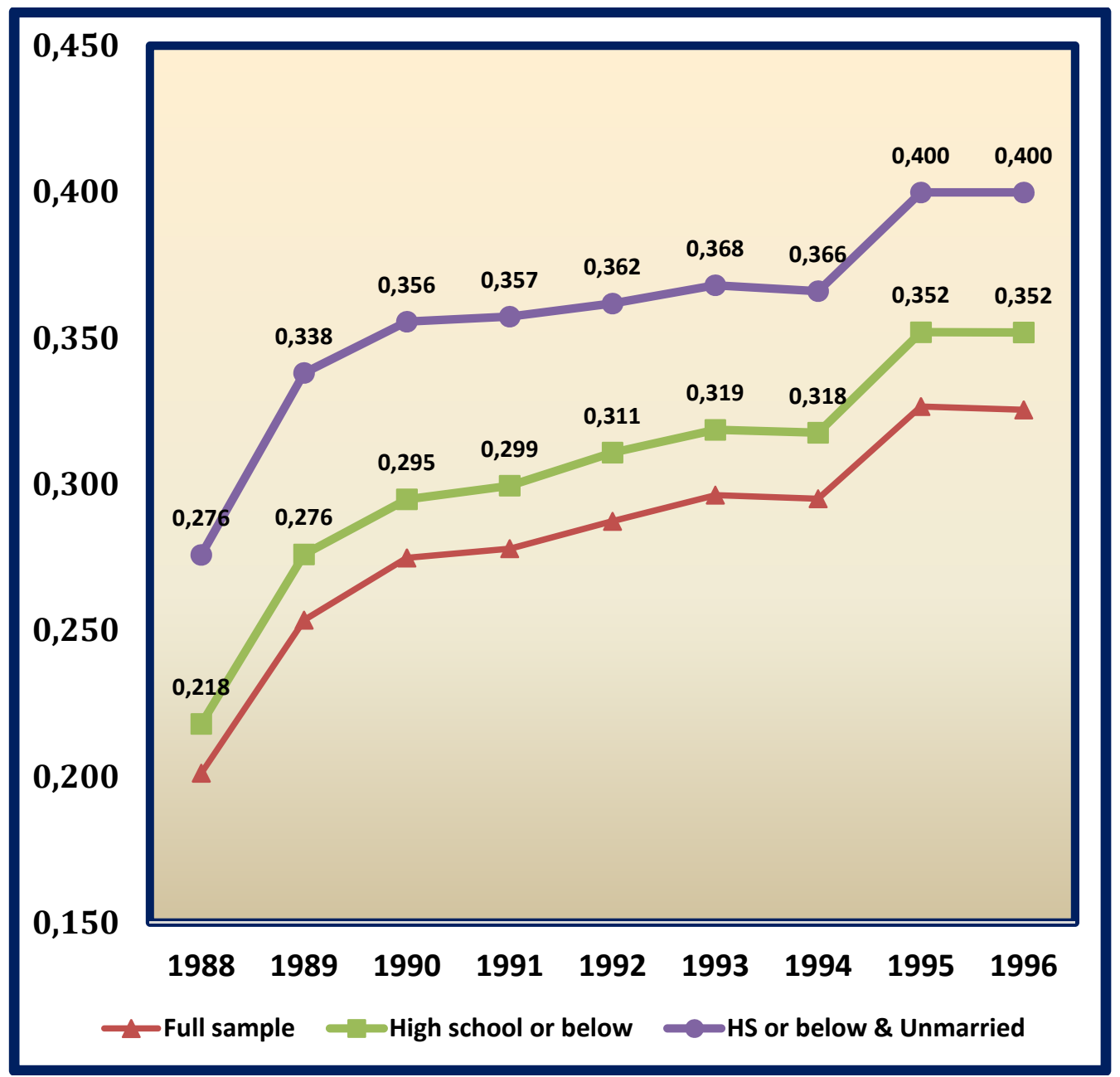


Table 1

Baseline (1989) Sample Means

Mothers Ages 18-39

\begin{tabular}{|c|c|c|c|c|}
\hline Sample: Births & All & High school or below & $\begin{array}{l}\text { Less than high school } \\
\text { Unmarried }\end{array}$ & $\begin{array}{l}\text { College \& above } \\
\text { Married }\end{array}$ \\
\hline Any prenatal smoking & 0.196 & 0.263 & 0.402 & 0.046 \\
\hline Smoking $>5$ cigarettes daily & 0.148 & 0.204 & 0.311 & 0.032 \\
\hline Smoking $>10$ cigarettes daily & 0.078 & 0.110 & 0.164 & 0.012 \\
\hline $\begin{array}{l}\text { Number of cigarettes smoked per day } \\
\text { (including } 0 \text { for non-smokers) }\end{array}$ & 2.420 & 3.370 & 5.177 & 0.452 \\
\hline Weight gain & 30.192 & 29.779 & 28.453 & 30.671 \\
\hline Weight gain $<15$ pounds & 0.071 & 0.087 & 0.122 & 0.035 \\
\hline Weight gain $<20$ pounds & 0.142 & 0.168 & 0.220 & 0.088 \\
\hline Weight gain $>35$ pounds & 0.272 & 0.272 & 0.250 & 0.254 \\
\hline Weight gain $>40$ pounds & 0.149 & 0.155 & 0.150 & 0.121 \\
\hline Gestational diabetes & 0.021 & 0.020 & 0.014 & 0.023 \\
\hline Gestational hypertension & 0.028 & 0.027 & 0.021 & 0.027 \\
\hline Gestational anemia & 0.018 & 0.021 & 0.029 & 0.011 \\
\hline $\begin{array}{l}\text { Any condition: Gestational diabetes, } \\
\text { hypertension, or anemia }\end{array}$ & 0.065 & 0.064 & 0.061 & 0.059 \\
\hline Adequate prenatal care & 0.691 & 0.606 & 0.384 & 0.877 \\
\hline Prenatal care visits & 10.993 & 10.374 & 8.441 & 12.326 \\
\hline Medicaid eligibility for pregnant women & 0.223 & 0.243 & 0.297 & 0.167 \\
\hline Age & 26.649 & 25.170 & 23.137 & 30.417 \\
\hline Some high school education & 0.197 & 0.326 & 1 & 0 \\
\hline High school graduate & 0.409 & 0.674 & 0 & 0 \\
\hline Some college & 0.214 & 0 & 0 & 0 \\
\hline College or above & 0.180 & 0 & 0 & 1 \\
\hline Married & 0.754 & 0.663 & 0 & 1 \\
\hline White & 0.799 & 0.772 & 0.631 & 0.881 \\
\hline Black & 0.157 & 0.189 & 0.334 & 0.057 \\
\hline Other Race & 0.044 & 0.039 & 0.035 & 0.062 \\
\hline Hispanic & 0.137 & 0.185 & 0.305 & 0.039 \\
\hline State unemployment rate & 5.457 & 5.518 & 5.504 & 5.287 \\
\hline $\begin{array}{l}\text { State private insurance rate among single } \\
\text { males with incomes below } 200 \% \text { FPL }\end{array}$ & 0.614 & 0.609 & 0.602 & 0.626 \\
\hline $\begin{array}{l}\text { State excise tax on cigarettes, in cents per } \\
\text { pack }\end{array}$ & 20.482 & 19.788 & 19.880 & 20.171 \\
\hline Observations & $3,806,973$ & $2,100,145$ & 312,725 & 599,434 \\
\hline
\end{tabular}

Notes: Observations listed represent the maximum number of observations for the given sample. Some variables have fewer observations due to missing information. Baseline sample represents births occurring in 1989. 
Table 2

Mothers 18 - 39, High School Educated or Below

Effects of Medicaid Eligibility for Pregnant Women on Health Behaviors

\begin{tabular}{|c|c|c|c|c|c|c|c|c|c|}
\hline Outcome & Smoke & $\begin{array}{l}\text { Smoke }>5 \\
\text { Cigarettes } \\
\text { Daily } \\
\end{array}$ & $\begin{array}{c}\text { Smoke }>10 \\
\text { Cigarettes } \\
\text { Daily } \\
\end{array}$ & $\begin{array}{l}\text { Weight Gain } \\
\text { (pounds) }\end{array}$ & $\begin{array}{l}\text { Weight Gain } \\
\quad<15 \text { lbs. }\end{array}$ & $\begin{array}{l}\text { Weight Gain } \\
<20 \text { lbs. }\end{array}$ & $\begin{array}{l}\text { Weight Gain } \\
>35 \mathrm{lbs} .\end{array}$ & $\begin{array}{l}\text { Weight Gain } \\
>40 \text { lbs. }\end{array}$ & $\begin{array}{c}\text { Any Condition } \\
\text { (Gestational diabetes, } \\
\text { hypertension, anemia) }\end{array}$ \\
\hline $\begin{array}{l}\text { Panel A } \\
\text { Eligibility }\end{array}$ & $\begin{array}{c}0.057 * * \\
(0.026)\end{array}$ & $\begin{array}{c}0.050^{* *} \\
(0.020)\end{array}$ & $\begin{array}{c}0.015 \\
(0.010)\end{array}$ & $\begin{array}{c}-0.887 * * \\
(0.339)\end{array}$ & $\begin{array}{c}0.012 \\
(0.008)\end{array}$ & $\begin{array}{c}0.019 \\
(0.012)\end{array}$ & $\begin{array}{c}-0.025^{* *} \\
(0.012)\end{array}$ & $\begin{array}{l}-0.014 \\
(0.009)\end{array}$ & $\begin{array}{c}0.006 \\
(0.005)\end{array}$ \\
\hline $\begin{array}{l}\text { Panel B } \\
0.20 \leq \text { Elig. }<0.30 \\
0.30 \leq \text { Elig. }<0.50 \\
\text { Eligibility } \geq 0.50\end{array}$ & $\begin{array}{c}0.029 * * * \\
(0.007) \\
0.041 * * * \\
(0.008) \\
-0.005 \\
(0.013)\end{array}$ & $\begin{array}{c}0.020 * * * \\
(0.005) \\
0.028 * * * \\
(0.006) \\
-0.003 \\
(0.010)\end{array}$ & $\begin{array}{c}0.003 \\
(0.002) \\
0.005^{*} \\
(0.003) \\
-0.003 \\
(0.004)\end{array}$ & $\begin{array}{c}0.116^{* *} \\
(0.047) \\
0.142^{* *} \\
(0.060) \\
-0.321^{* * *} \\
(0.099)\end{array}$ & $\begin{array}{c}0.002 * \\
(0.001) \\
0.002 \\
(0.001) \\
0.003 \\
(0.003)\end{array}$ & $\begin{array}{c}0.002 \\
(0.001) \\
0.002 \\
(0.002) \\
0.006 \\
(0.003)\end{array}$ & $\begin{array}{c}0.006 * * * \\
(0.001) \\
0.007 * * * \\
(0.002) \\
-0.012 * * * \\
(0.004)\end{array}$ & $\begin{array}{c}0.006^{* * *} \\
(0.001) \\
0.008^{* * *} \\
(0.002) \\
-0.009^{* *} \\
(0.004)\end{array}$ & $\begin{array}{c}0.002 * \\
(0.001) \\
0.001 \\
(0.001) \\
0.002 \\
(0.002)\end{array}$ \\
\hline $\begin{array}{l}1989 \text { Mean Outcome } \\
\text { Observations }\end{array}$ & $\begin{array}{c}0.263 \\
13,183,072 \\
\end{array}$ & $\begin{array}{c}0.204 \\
13,028,184\end{array}$ & $\begin{array}{c}0.110 \\
13,028,184\end{array}$ & $\begin{array}{c}29.78 \\
12,901,569 \\
\end{array}$ & $\begin{array}{c}0.087 \\
12,754,647 \\
\end{array}$ & $\begin{array}{c}0.168 \\
12,754,647\end{array}$ & $\begin{array}{c}0.272 \\
12,754,647 \\
\end{array}$ & $\begin{array}{c}0.155 \\
12,754,647 \\
\end{array}$ & $\begin{array}{c}0.064 \\
17,154,854\end{array}$ \\
\hline
\end{tabular}

Notes: All models control for maternal age, education, race, indicators for education* race, ethnicity, state unemployment rate (contemporaneous, lag,

lead), state private insurance rate among low-income ( $<200 \%$ FPL) single males, outcome mean among college-educated married pregnant women between the ages of 25-39, and state*race, state*age category (18-24, 25-29, 30-34, 35-39), year*race, and year*age category effects. Models for weight gain also control for indicators for gestation in weeks. For non-linear models in Panel B, marginal effects at eligibility thresholds $(0.20-0.40$ in increments of 0.05 ) are reported. Standard errors are clustered within state cells and reported in parentheses. Asterisks denote statistical significance as follows: ***p-value $\leq 0.01 ; * * 0.01<\mathrm{p}$-value $\leq 0.05 ; * 0.05<\mathrm{p}$-value $\leq 0.10$. 
Table 3

Mothers 18 - 39, Less-than-High School Educated, Unmarried

\begin{tabular}{|c|c|c|c|c|c|c|c|c|c|}
\hline Outcome & Smoke & $\begin{array}{l}\text { Smoke }>5 \\
\text { Cigarettes } \\
\text { Daily }\end{array}$ & $\begin{array}{c}\text { Smoke }>10 \\
\text { Cigarettes } \\
\text { Daily }\end{array}$ & $\begin{array}{l}\text { Weight Gain } \\
\text { (pounds) }\end{array}$ & $\begin{array}{l}\text { Weight Gain } \\
<15 \text { lbs. }\end{array}$ & $\begin{array}{l}\text { Weight Gain } \\
<20 \text { lbs. }\end{array}$ & $\begin{array}{c}\text { Weight Gain } \\
>35 \mathrm{lbs} .\end{array}$ & $\begin{array}{c}\text { Weight Gain } \\
>40 \text { lbs. }\end{array}$ & $\begin{array}{c}\text { Any Condition } \\
\text { (Gestational diabetes, } \\
\text { hypertension, anemia) }\end{array}$ \\
\hline $\begin{array}{l}\text { Panel A } \\
\text { Eligibility }\end{array}$ & $\begin{array}{c}0.055 \\
(0.037)\end{array}$ & $\begin{array}{c}0.052 \\
(0.034)\end{array}$ & $\begin{array}{c}0.001 \\
(0.021)\end{array}$ & $\begin{array}{c}-1.353 * * \\
(0.560)\end{array}$ & $\begin{array}{c}0.022 \\
(0.014)\end{array}$ & $\begin{array}{c}0.027 \\
(0.020)\end{array}$ & $\begin{array}{c}-0.037 * * \\
(0.015)\end{array}$ & $\begin{array}{c}-0.026^{* *} \\
(0.012)\end{array}$ & $\begin{array}{c}0.008 \\
(0.011)\end{array}$ \\
\hline $\begin{array}{l}\text { Panel B } \\
0.20 \leq \text { Elig. }<0.30 \\
0.30 \leq \text { Elig. }<0.50 \\
\text { Eligibility } \geq 0.50\end{array}$ & $\begin{array}{c}0.040^{* * *} \\
(0.014) \\
0.051 * * * \\
(0.015) \\
0.011 \\
(0.014)\end{array}$ & $\begin{array}{c}0.024^{* *} \\
(0.011) \\
0.029 * * \\
(0.012) \\
0.006 \\
(0.009)\end{array}$ & $\begin{array}{c}-0.008 \\
(0.006) \\
-0.012 * * \\
(0.005) \\
-0.013 * * \\
(0.006)\end{array}$ & $\begin{array}{c}0.117 \\
(0.085) \\
0.047 \\
(0.108) \\
-0.272^{*} \\
(0.159)\end{array}$ & $\begin{array}{c}0.003^{*} \\
(0.001) \\
0.005^{*} \\
(0.002) \\
0.006 \\
(0.004)\end{array}$ & $\begin{array}{c}0.003^{*} \\
(0.002) \\
0.006^{*} \\
(0.003) \\
0.009 \\
(0.005)\end{array}$ & $\begin{array}{c}0.007 * * \\
(0.003) \\
0.008 * * \\
(0.003) \\
-0.006 \\
(0.005)\end{array}$ & $\begin{array}{c}0.007 * * * \\
(0.002) \\
0.007 * * \\
(0.003) \\
-0.004 \\
(0.004)\end{array}$ & $\begin{array}{c}-0.000 \\
(0.002) \\
-0.001 \\
(0.003) \\
0.003 \\
(0.004)\end{array}$ \\
\hline $\begin{array}{l}1989 \text { Mean Outcome } \\
\text { Observations }\end{array}$ & $\begin{array}{c}0.402 \\
2,086,831\end{array}$ & $\begin{array}{c}0.311 \\
2,051,850\end{array}$ & $\begin{array}{c}0.164 \\
2,051,850\end{array}$ & $\begin{array}{c}28.45 \\
1,962,883\end{array}$ & $\begin{array}{c}0.122 \\
1,933,615\end{array}$ & $\begin{array}{c}0.220 \\
1,933,615\end{array}$ & $\begin{array}{c}0.250 \\
1,933,615\end{array}$ & $\begin{array}{c}0.150 \\
1,933,615\end{array}$ & $\begin{array}{c}0.061 \\
2,927,940\end{array}$ \\
\hline
\end{tabular}

Notes: See Table 2. 
Table 4

Mothers 18 - 39, High School Educated or Below

\section{Controlling for Prenatal Care}

\begin{tabular}{|c|c|c|c|c|c|c|c|c|c|}
\hline Outcome & Smoke & $\begin{array}{c}\text { Smoke }>5 \\
\text { Cigarettes } \\
\text { Daily } \\
\end{array}$ & $\begin{array}{c}\text { Smoke }>10 \\
\text { Cigarettes } \\
\text { Daily } \\
\end{array}$ & $\begin{array}{l}\text { Weight Gain } \\
\text { (pounds) }\end{array}$ & $\begin{array}{l}\text { Weight Gain } \\
<15 \text { lbs. }\end{array}$ & $\begin{array}{l}\text { Weight Gain } \\
<20 \mathrm{lbs} \text {. }\end{array}$ & $\begin{array}{l}\text { Weight Gain } \\
>35 \mathrm{lbs} \text {. }\end{array}$ & $\begin{array}{c}\text { Weight Gain } \\
>40 \mathrm{lbs} .\end{array}$ & $\begin{array}{c}\text { Any Condition } \\
\text { (Gestational diabetes, } \\
\text { hypertension, anemia) }\end{array}$ \\
\hline $\begin{array}{l}\text { Panel A } \\
\text { Eligibility }\end{array}$ & $\begin{array}{c}0.058 * * \\
(0.025)\end{array}$ & $\begin{array}{c}0.052 * * \\
(0.020)\end{array}$ & $\begin{array}{c}0.016 \\
(0.010)\end{array}$ & $\begin{array}{c}-1.099 * * * \\
(0.385)\end{array}$ & $\begin{array}{l}0.014 * \\
(0.008)\end{array}$ & $\begin{array}{l}0.022^{*} \\
(0.011)\end{array}$ & $\begin{array}{c}-0.032 * * \\
(0.013)\end{array}$ & $\begin{array}{l}-0.019 * \\
(0.010)\end{array}$ & $\begin{array}{c}0.004 \\
(0.005)\end{array}$ \\
\hline $\begin{array}{l}\text { Panel B } \\
0.20 \leq \text { Elig. }<0.30 \\
0.30 \leq \text { Elig. }<0.50 \\
\text { Eligibility } \geq 0.50\end{array}$ & $\begin{array}{c}0.027 * * * \\
(0.006) \\
0.040 * * * \\
(0.008) \\
-0.005 \\
(0.013)\end{array}$ & $\begin{array}{c}0.019 * * * \\
(0.005) \\
0.027 * * * \\
(0.006) \\
-0.002 \\
(0.009)\end{array}$ & $\begin{array}{c}0.003 \\
(0.002) \\
0.004^{*} \\
(0.003) \\
-0.002 \\
(0.004)\end{array}$ & $\begin{array}{c}0.114^{* *} \\
(0.053) \\
0.116 \\
(0.070) \\
-0.414^{* * *} \\
(0.108)\end{array}$ & $\begin{array}{c}0.002 * * \\
(0.001) \\
0.002 * \\
(0.001) \\
0.004 \\
(0.002)\end{array}$ & $\begin{array}{c}0.002^{*} \\
(0.001) \\
0.002 \\
(0.002) \\
0.007 * * \\
(0.003)\end{array}$ & $\begin{array}{c}0.006^{* * *} \\
(0.002) \\
0.006^{* *} \\
(0.002) \\
-0.015^{* * *} \\
(0.005)\end{array}$ & $\begin{array}{c}0.005 * * * \\
(0.001) \\
0.007 * * * \\
(0.002) \\
-0.011^{* * *} \\
(0.004)\end{array}$ & $\begin{array}{c}0.002 * * \\
(0.001) \\
0.001 \\
(0.001) \\
0.001 \\
(0.002)\end{array}$ \\
\hline $\begin{array}{l}1989 \text { Mean Outcome } \\
\text { Observations }\end{array}$ & $\begin{array}{c}0.263 \\
12,692,154\end{array}$ & $\begin{array}{c}0.204 \\
12,550,241 \\
\end{array}$ & $\begin{array}{c}0.110 \\
12,550,241\end{array}$ & $\begin{array}{c}29.78 \\
12,553,007 \\
\end{array}$ & $\begin{array}{c}0.087 \\
12,412,191 \\
\end{array}$ & $\begin{array}{c}0.168 \\
12,412,191 \\
\end{array}$ & $\begin{array}{c}0.272 \\
12,412,191 \\
\end{array}$ & $\begin{array}{c}0.155 \\
12,412,191 \\
\end{array}$ & $\begin{array}{c}0.064 \\
16,413,750 \\
\end{array}$ \\
\hline
\end{tabular}

Notes: All models control for the number of prenatal care visits, and the adequacy of prenatal care based on the number of visits and initiation/timing (using the Kotelchuck criteria). Also see notes to Table 2. 
Table 5

Mothers 25 - 39, College Educated \& Above, Married

Effects of Medicaid Eligibility for Pregnant Women on Health Behaviors

\begin{tabular}{|c|c|c|c|c|c|c|c|c|c|}
\hline Outcome & Smoke & $\begin{array}{c}\text { Smoke }>5 \\
\text { Cigarettes } \\
\text { Daily } \\
\end{array}$ & $\begin{array}{c}\text { Smoke }>10 \\
\text { Cigarettes } \\
\text { Daily } \\
\end{array}$ & $\begin{array}{l}\text { Weight Gain } \\
\text { (pounds) }\end{array}$ & $\begin{array}{l}\text { Weight Gain } \\
\quad<15 \text { lbs. }\end{array}$ & $\begin{array}{l}\text { Weight Gain } \\
<20 \mathrm{lbs} \text {. }\end{array}$ & $\begin{array}{c}\text { Weight Gain } \\
>35 \text { lbs. }\end{array}$ & $\begin{array}{l}\text { Weight Gain } \\
>40 \text { lbs. }\end{array}$ & $\begin{array}{c}\text { Any Condition } \\
\text { (Gestational diabetes, } \\
\text { hypertension, anemia) }\end{array}$ \\
\hline $\begin{array}{l}\text { Panel A } \\
\text { Eligibility }\end{array}$ & $\begin{array}{l}-0.002 \\
(0.006)\end{array}$ & $\begin{array}{l}-0.002 \\
(0.006)\end{array}$ & $\begin{array}{l}-0.000 \\
(0.002)\end{array}$ & $\begin{array}{c}0.295 \\
(0.522)\end{array}$ & $\begin{array}{l}-0.004 \\
(0.006)\end{array}$ & $\begin{array}{l}-0.005 \\
(0.010)\end{array}$ & $\begin{array}{c}0.011 \\
(0.018)\end{array}$ & $\begin{array}{c}0.003 \\
(0.013)\end{array}$ & $\begin{array}{c}0.014 \\
(0.009)\end{array}$ \\
\hline $\begin{array}{l}\text { Panel B } \\
\text { Eligibility }\end{array}$ & $\begin{array}{l}-0.001 \\
(0.009)\end{array}$ & $\begin{array}{c}0.001 \\
(0.007)\end{array}$ & $\begin{array}{c}0.001 \\
(0.002)\end{array}$ & $\begin{array}{c}0.193 \\
(0.448)\end{array}$ & $\begin{array}{l}-0.007 \\
(0.006)\end{array}$ & $\begin{array}{l}-0.006 \\
(0.010)\end{array}$ & $\begin{array}{c}0.004 \\
(0.018)\end{array}$ & $\begin{array}{l}-0.000 \\
(0.011)\end{array}$ & $\begin{array}{c}0.012 \\
(0.009)\end{array}$ \\
\hline $\begin{array}{l}\text { Panel C } \\
\text { Eligibility }\end{array}$ & $\begin{array}{l}-0.016 \\
(0.011)\end{array}$ & $\begin{array}{l}-0.013 \\
(0.010)\end{array}$ & $\begin{array}{l}-0.000 \\
(0.001)\end{array}$ & $\begin{array}{c}0.471 \\
(0.359)\end{array}$ & $\begin{array}{c}-0.010^{*} \\
(0.005)\end{array}$ & $\begin{array}{l}-0.010 \\
(0.010)\end{array}$ & $\begin{array}{c}0.014 \\
(0.012)\end{array}$ & $\begin{array}{c}0.005 \\
(0.009)\end{array}$ & $\begin{array}{c}0.007 \\
(0.010)\end{array}$ \\
\hline $\begin{array}{l}1989 \text { Mean } \\
\text { Observations }\end{array}$ & $\begin{array}{c}0.046 \\
4,415,918 \\
\end{array}$ & $\begin{array}{c}0.032 \\
4,407,371\end{array}$ & $\begin{array}{c}0.013 \\
4,407,371 \\
\end{array}$ & $\begin{array}{c}30.63 \\
4,497,365\end{array}$ & $\begin{array}{c}0.035 \\
4,474,859\end{array}$ & $\begin{array}{c}0.088 \\
4,474,859\end{array}$ & $\begin{array}{c}0.252 \\
4,4748,59\end{array}$ & $\begin{array}{c}0.120 \\
4,474,859\end{array}$ & $\begin{array}{c}0.059 \\
5,448,191\end{array}$ \\
\hline
\end{tabular}

Notes: See notes to Table 2. Panel A includes state and year fixed effects. Panel B adds state*age, state*race, year*age, and year*race fixed effects.

Panel $\mathrm{C}$ adds state-specific linear trends. 
Appendix Table A1

Mothers 18 - 39, High School Educated or Below

\section{Effects of Medicaid Eligibility for Pregnant Women on Health Behaviors}

Controlling for State-Specific Trends

\begin{tabular}{|c|c|c|c|c|c|c|c|c|c|}
\hline Outcome & Smoke & $\begin{array}{l}\text { Smoke }>5 \\
\text { Cigarettes } \\
\text { Daily }\end{array}$ & $\begin{array}{l}\text { Smoke }>10 \\
\text { Cigarettes } \\
\text { Daily }\end{array}$ & $\begin{array}{l}\text { Weight Gain } \\
\text { (pounds) }\end{array}$ & $\begin{array}{l}\text { Weight Gain } \\
<15 \text { lbs. }\end{array}$ & $\begin{array}{l}\text { Weight Gain } \\
<20 \text { lbs. }\end{array}$ & $\begin{array}{c}\text { Weight Gain } \\
>35 \text { lbs. }\end{array}$ & $\begin{array}{c}\text { Weight Gain } \\
>40 \mathrm{lbs} .\end{array}$ & $\begin{array}{c}\text { Any Condition } \\
\text { (Gestational diabetes, } \\
\text { hypertension, anemia) }\end{array}$ \\
\hline $\begin{array}{l}\text { Panel A } \\
\text { Eligibility }\end{array}$ & $\begin{array}{c}0.072 * * * \\
(0.026)\end{array}$ & $\begin{array}{c}0.050 * * * \\
(0.018)\end{array}$ & $\begin{array}{c}0.006 \\
(0.007)\end{array}$ & $\begin{array}{l}-0.727^{*} \\
(0.416)\end{array}$ & $\begin{array}{c}0.017 * * \\
(0.007)\end{array}$ & $\begin{array}{c}0.030^{* *} \\
(0.011)\end{array}$ & $\begin{array}{l}-0.014 \\
(0.012)\end{array}$ & $\begin{array}{l}-0.001 \\
(0.009)\end{array}$ & $\begin{array}{c}0.004 \\
(0.005)\end{array}$ \\
\hline $\begin{array}{l}\text { Panel B } \\
0.20 \leq \text { Elig. }<0.30 \\
0.30 \leq \text { Elig. }<0.50 \\
\text { Eligibility } \geq 0.50\end{array}$ & $\begin{array}{c}0.033 * * * \\
(0.006) \\
0.047 * * * \\
(0.007) \\
0.001 \\
(0.013)\end{array}$ & $\begin{array}{c}0.023 * * * \\
(0.005) \\
0.031^{* * *} \\
(0.005) \\
-0.000 \\
(0.009)\end{array}$ & $\begin{array}{c}0.005^{* *} \\
(0.002) \\
0.005^{* *} \\
(0.002) \\
-0.003 \\
(0.004)\end{array}$ & $\begin{array}{c}0.108 * * \\
(0.051) \\
0.162 * * \\
(0.077) \\
-0.273 * * \\
(0.118)\end{array}$ & $\begin{array}{c}0.002 * * * \\
(0.001) \\
0.003 * * \\
(0.001) \\
0.004 * * \\
(0.002)\end{array}$ & $\begin{array}{c}0.003 * * \\
(0.001) \\
0.004 * \\
(0.002) \\
0.009 * * * \\
(0.003)\end{array}$ & $\begin{array}{c}0.006 * * * \\
(0.002) \\
0.009 * * * \\
(0.002) \\
-0.008 * \\
(0.004)\end{array}$ & $\begin{array}{c}0.006 * * * \\
(0.001) \\
0.010 * * * \\
(0.002) \\
-0.005 \\
(0.004)\end{array}$ & $\begin{array}{c}0.001 \\
(0.001) \\
0.001 \\
(0.001) \\
0.001 \\
(0.002)\end{array}$ \\
\hline $\begin{array}{l}1989 \text { Mean Outcome } \\
\text { Observations }\end{array}$ & $\begin{array}{c}0.263 \\
13,183,072\end{array}$ & $\begin{array}{c}0.204 \\
13,028,184\end{array}$ & $\begin{array}{c}0.110 \\
13,028,184\end{array}$ & $\begin{array}{c}29.78 \\
12,901,569\end{array}$ & $\begin{array}{c}0.087 \\
12,754,647\end{array}$ & $\begin{array}{c}0.168 \\
12,754,647\end{array}$ & $\begin{array}{c}0.272 \\
12,754,647\end{array}$ & $\begin{array}{c}0.155 \\
12,754,647\end{array}$ & $\begin{array}{c}0.064 \\
17,154,854\end{array}$ \\
\hline
\end{tabular}

Notes: All models control for maternal age, education, race, indicators for education* race, ethnicity, state unemployment rate (contemporaneous, lag, lead), state private insurance rate among low-income $(<200 \%$ FPL) single males, outcome mean among college-educated married pregnant women between the ages of 25-39, and state*race, state*age category (18-24, 25-29, 30-34, 35-39), year*race, and year*age category effects. Models for weight gain also control for indicators for gestation in weeks. For non-linear models in Panel B, marginal effects at eligibility thresholds $(0.20-0.40$ in increments of 0.05 ) are reported. Standard errors are clustered within state cells and reported in parentheses. Asterisks denote statistical significance as follows: $* * *$ p-value $\leq 0.01 ; * * 0.01<$ p-value $\leq 0.05 ; * 0.05<$ p-value $\leq 0.10$. 